\title{
SISTEMAS TRANSPORTADORES DE DROGAS
}

\author{
Maria Luiza C. Montanari; Carlos Alberto Montanari e Dorila Piló-Veloso \\ Departamento de Química/ICEx/UFMG - Campus da Pampulha - 31270-901 - Belo Horizonte - MG \\ A. E. Beezer e J. C. Mitchell \\ Chemical Laboratory - University of Kent at Canterbury - UK
}

Recebido em 22/5/95; aceito em 17/12/97

\begin{abstract}
DRUG DELIVERY SYSTEMS. Drug delivery system controls the distribution of drugs for optimal therapeutic efficacy. The complex of higly active drugs with macromolecular carriers seems to offer a promising way to optimize their delivery. Dendrimers can be used as drug delivery system and this paper addresses the effectivenes of the approach. The host-guest system improves the solubility of hydrazides and mesoionic 1,3,4-thiadiazolium-2-aminide compounds.
\end{abstract}

Keywords: dendrimers; drug delivery; solubility.

\section{INTRODUÇÃO}

Em uma de suas aplicações, a química está convencionalmente associada com a "construção" de micromoléculas algumas vezes estruturalmente complexas (como por exemplo, a síntese de 40 etapas do taxol ${ }^{1}$, Figura 1). Mas, ela também preocupa-se com a síntese de macromoléculas muito mais complexas, tais como proteínas e ácidos nucléicos. Com a introdução de novos domínios científicos, no entendimento da topologia molecular e a orientação de grupos funcionais (por exemplo, a biologia molecular), é possível estabelecer esforços no sentido de atuar nesses dois extremos da síntese orgânica. $\mathrm{O}$ estudo da química supramolecular, e, em particular a química dendrimérica, pode constituir um método útil na resolução de novos problemas sintéticos ${ }^{2}$.

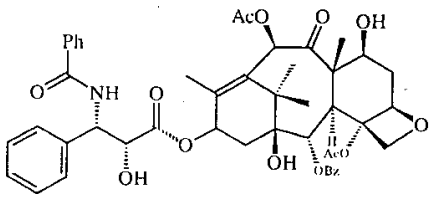

Figura 1. Estrutura molecular do taxol.

A descoberta de éteres coroas por Pedersen ${ }^{3,4}$, em 1967, e as pesquisas de $\mathrm{Cram}^{5,6} \mathrm{e} \mathrm{Lehn}^{7,8}$, estabeleceram um novo campo da química - interações específicas e altamente seletivas, que garantiram aos mesmos o prêmio Nobel em Química no ano de 1987. A química supramolecular, como tem sido chamada, é melhor descrita através do seguinte:

"a química supramolecular é a química da ligação intermolecular, referente à estrutura e função das entidades formadas pela associação de duas ou mais espécies químicas" Jean-Marie Lehn ${ }^{7 b}$

A ligação intermolecular pode ser estabelecida através de par iônico, interação hidrofóbica ou hidrofílica, ligação de hidrogênio, hospedeiro-convidado, e, interações $\pi-\pi$ que mantêm complexos unidos. Muitos sistemas biológicos, como enzimas e anticorpos, participam de reações com elevada ou quase perfeita seletividade pela formação de complexos não-covalentes com o substrato ${ }^{9}$. Em tais complexos, o substrato está acomodado dentro da cavidade da enzima para maximizar o contato com a sua superfície. Esse "encaixe complementar" ocorre em "sítios" múltiplos, apropriadamente localizados e orientados, que são adequados para propiciar a interação. Embora a energia de interação com cada sítio seja tipicamente de poucos Joules/mol (muito menor do que a ligação covalente), o efeito cumulativo resulta em uma forte interação do substrato com o sítio ativo da enzima. Então, um requisito fundamental para o reconhecimento estrutural é o principio da complementaridade ${ }^{10}$ ou seja, para que haja a formação do complexo, o "hospedeiro" deve possuir sítios de interações que possibilitem cooperativamente o contato e a atração dos sítios de interação do "convidado" sem gerar fortes repulsões não-ligantes ${ }^{11}$. A força da associação e, consequentemente, a seletividade do "hospedeiro", dependem da préorganização do receptor antes da complexação: se a reorganização do sítio de interação for favorável, então este processo resultará na perda de energia livre de interação e dessa forma reduzirá a força resultante do complexo ${ }^{7}$.

Os químicos que estão trabalhando no campo da química supramolecular desejam sintetizar compostos simples que sejam "hospedeiros" e que sejam capazes de imitar receptores biológicos até alcançar-se reações altamente seletivas ${ }^{12-14}$. Eles também estudam as interações não-covalentes que são características de complexos "hospedeiro-convidado". Entretanto, não é muito fácil fazer uma previsão do grau de rigidez necessário para modelar os receptores e uma alta rigidez, em geral, previne qualquer complexação de ocorrer. Portanto, a maioria dos hospedeiros sintéticos incorpora uma certa flexibilidade que permite um "ajuste" conformacional durante a complexação com o "convidado".

No caso de receptores (ou aceptores) solúveis em água, a força-motriz para a complexação de "convidados" neutros é constituída predominantemente da remoção do contato entre o solvente (água) e o "convidado". Este é o caso dos aceptores naturais chamados de ciclodextrinas e seus análogos sintéticos ciclofanos.

As ciclodextrinas ${ }^{15,16}$ são oligossacarídios de unidades de açúcares que formam uma estrutura em forma de um compartimento cilíndrico. A menor delas, a $\alpha$-ciclodextrina, figura 2 , forma complexos com substratos orgânicos e inorgânicos, tais como $\mathrm{I}_{3}^{-}$e fenóis $p$-substituídos e, também tem sido usada para catalisar reações ${ }^{17}, 18$.

Ciclofanos solúveis em água mas que apresentam cavidades hidrofóbicas têm sido sintetizados ${ }^{19,20}$. Um exemplo de ciclofano catalisador é mostrado na figura $3^{19 \mathrm{c}}$. Este, forma complexos estequiométricos de inclusão com acetatos de nitronaftila em tampões fosfato e catalisa a hidrólise dos substratos ligados ${ }^{21,22}$. 


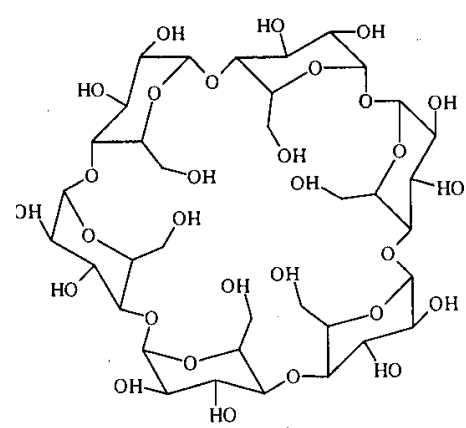

Figura 2. $\alpha$-Ciclodextrina.

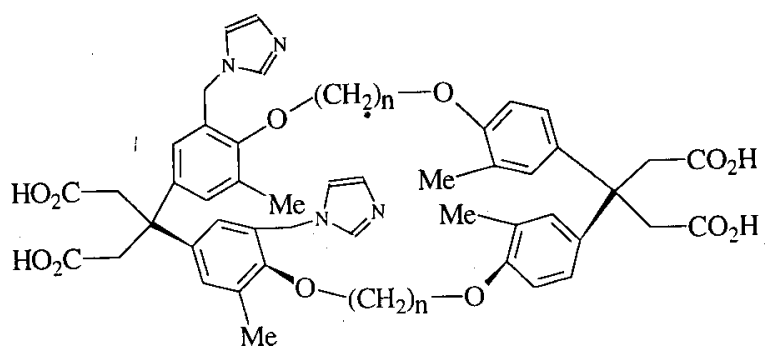

Figura 3. Um exemplo de ciclofano catalisador.

\section{FORÇAS QUE GOVERNAM AS INTERAÇÕES HOSPEDEIRO-CONVIDADO ${ }^{23-27}$}

As interações eletrostáticas são governadas pela energia de associação de duas cargas elétricas separadas por uma certa distância e determinam, através da lei de Coulomb, o "trabalho" necessário para separar essas cargas por uma distância infinita. As interações hospedeiro-convidado podem ser iônicas; dipolo-dipolo. As associações entre moléculas eletricamente neutras, conhecidas como forças de van der Waals, originam-se das interações eletrostáticas entre dipolos permanente e/ou dipolos induzidos. A ligação de hidrogênio é um caso especial da interação dipolar que será considerada à parte. As forças de dispersão de London que resultam de uma "flutuação" rápida dos elétrons são extremamente fracas. Elas são significativas apenas para grupos que se contatam. Entretanto, o grande número de contatos interatômicos em proteínas faz com que as forças de London influenciem sobremaneira suas conformações.

As interações por ligação de hidrogênio são predominantemente eletrostáticas e ocorrem entre grupos doadores fracos (D) e átomos aceptores (A) que possuam pelo menos um par de elétrons não-compartilhados. Em sistemas biológicos D e A podem ser átomos altamente eletronegativos como $\mathrm{N}$ e $\mathrm{O}$ e raramente $\mathrm{S}$. A grande diferença com as forças de van de Waals é que as ligações de hidrogênio são muito mais direcionais. $\mathrm{O}$ exemplo mais típico da formação de ligações de hidrogênio refere-se à estrutura de dupla-hélice do DNA, que envolve duas fitas complementares mantidas através dessas ligações de hidrogênio entre os pares de bases nitrogenadas adenina e timina, $\mathrm{AT}$, e citosina e guanina, $\mathrm{CG}^{28,29}$. Esta interação não-covalente tem, portanto, recebido muita atenção dos químicos sintéticos e medicinais que almejam o desenvolvimento de receptores capazes de interagir com substâncias de interesse biológico. A figura $4^{30}$ mostra um receptor geral formando complexos com barbituratos, que são importantes em anestesia e como anticonvulsivantes ${ }^{30}$. A interação eficiente ocorre quando a cavidade tem tamanho apropriado e, por exemplo, quando as ligações de hidrogênio são estabelecidas. Pela variação dos grupos "espaçadores" ou "ponte", a rigidez e o tamanho do receptor podem ser otimizados para cada substrato.

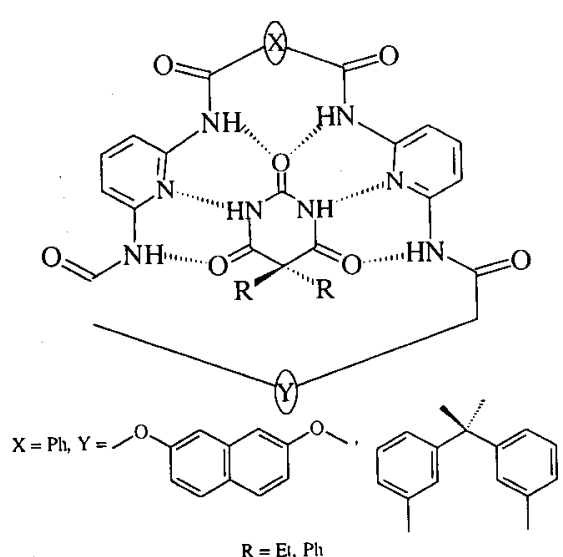

Figura 4. Exemplo de um receptor contendo substrato ligado por ligação de hidrogênio.

As interações $\pi$ - $\pi$ que ocorrem em subunidades aromáticas podem, por exemplo, estabilizar a estrutura helicoidal da dupla hélice do DNA. Além disso, substratos aromáticos planos são conhecidos como intercaladores entre os pares de bases nitrogenadas, e por isso têm merecido a atenção de muitos pesquisadores. Esse interesse não se dá, entretanto, apenas com relação a sistemas com importância biológica, mas também para possibilitar um entendimento mais fundamental do efeito em si. Os anéis aromáticos estão dispostos "face-a-face" de modo a estabelecer um arranjo espacial ideal para as interações $\pi-\pi^{31} 34$.

As interações por ligação de hidrogênio com o sistema $\pi$ de uma estrutura aromática ${ }^{35}$ também são importantes em sistemas biológicos.

As interações cátion- $\pi^{36-39}$ intermoleculares não-covalentes têm, de maneira geral, sido negligenciadas mas, no entanto, são importantes na topologia das estruturas de macromoléculas biológicas. Elas também atuam na mediação de processos de interação receptor-ligante, enzima-substrato e no reconhecimento antígenoanticorpo. As interações cátion- $\pi$ são importantes nos processos de reconhecimento biológico quando ocorrem com cadeias laterais aromáticas dos aminoácidos fenilalanina, Phe, tirosina, $T y r$, e triptofano, Trp. Essas interações já foram mostradas em modelos conhecidos - os cavitandos, por exemplo através de compostos chamados calixarenos $^{40-42}$, mas somente agora reconhece-se que se tratam interações surpreendentemente fortes ${ }^{36}$.

\section{MACROMOLÉCULAS DENDRIMÉRICAS ${ }^{43,44}$}

Na química sintética, dendrímeros são considerados "intermediários" entre moléculas comuns ou convencionais e a tradicional química de polímeros. A "química dendrimérica" (cascatas, arboróis e dendrímeros) está expandindo esses limites sintéticos. Essas moléculas/polímeros são fundamentadas na aplicação de progressões matemáticas para a síntese orgânica e, como tal, possuem uma topologia molecular bem definida.

Os dendrímeros são altamente ramificados. Essas macromoléculas tridimensionais possuem pontos de ramificação em cada unidade monomérica que são capazes de conduzir a estruturas com definidos números de geração e grupos funcionais terminais. Elas apresentam, ainda, elevado controle do peso molecular e da forma, o que proporciona a síntese de micelas unimoleculares. A figura 5 mostra uma estrutura dendrítica altamente ramificada ${ }^{45,46}$.

Os dendrímeros são preparados através de uma síntese tridimensional repetitiva. Como resultado desse procedimento controlado, os dendrímeros têm sido comparados com polímeros esféricos monodispersos ${ }^{47}$. Esses polímeros dendriméricos diferem dos polímeros clássicos em quatro áreas distintas: (i) simetria; (ii) grau de ramificação; (iii) funcionalização terminal e (iv) monodispersão. 


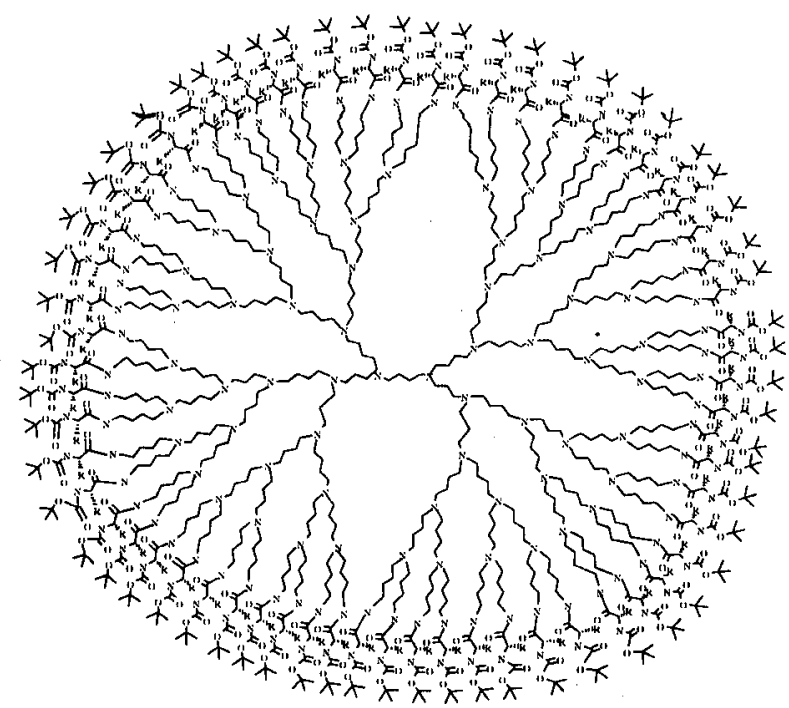

Figura 5. Estrutura dendrítica ramificada.

As sínteses dendriméricas envolvem um núcleo a partir do qual gerações ramificadas estendem-se concentricamente. Esta ramificação dá-se através de uma progressão geométrica bem definida, figura 6 .

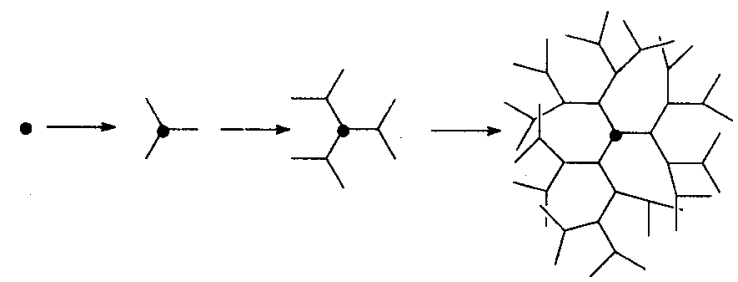

Figura 6. Representação esquemática do crescimento dendrimérico.

A arquitetura molecular pode adquirir o espaço tridimensional, com uma ramificação radial regular e, conduzir a uma molécula altamente simétrica.

A síntese 3D envolve o uso de núcleos polifuncionais que acumulam unidades monoméricas repetitivas de modo radial e exponencial, capaz de construir "braço-sobre-braço" até que uma topologia semelhante a uma árvore seja estabelecida. Veja a figura 6.

Os grupos terminais na síntese dendrimérica são usados no próximo estágio do "crescimento" molecular e, para cada nova geração que é formada o número de grupos terminais irá, pelo menos, dobrar. Através de um planejamento cuidadoso, a natureza e o número de grupos terminais podem ser controlados precisamente. Esta característica é importante na arquitetura dendrimérica, já que muitas aplicações potenciais podem e utilizam esta propriedade.

A síntese de dendrímeros representa um procedimento "passo-a-passo" muito bem controlado. A estratégia sintética repetitiva permite um controle do peso molecular e do tamanho, conduzindo a moléculas monodispersas.

A arquitetura dendrimérica é composta de três importantes elementos. Primeiramente, existe um núcleo central que, no caso mais simples, determina a extensão inicial, a orientação e a ramificação. Por exemplo, o núcleo rígido de adamantano (1, Figura 7) usado por Newkome ${ }^{48}$. Mais recentemente, entretanto, a importância do núcleo tem sido ressaltada. Fréchet ${ }^{49}$ e Inoue $^{50}$ propuseram, independentemente, o uso de porfirina como núcleo central, por exemplo 2 , figura 7 , enquanto que Diederich $^{51}$ propôs o uso de ciclofanos, por exemplo $\mathbf{3}$, figura 7. Esses núcleos propiciam o estudo da interação com estequiometria 1:1 no centro do dendrímero.
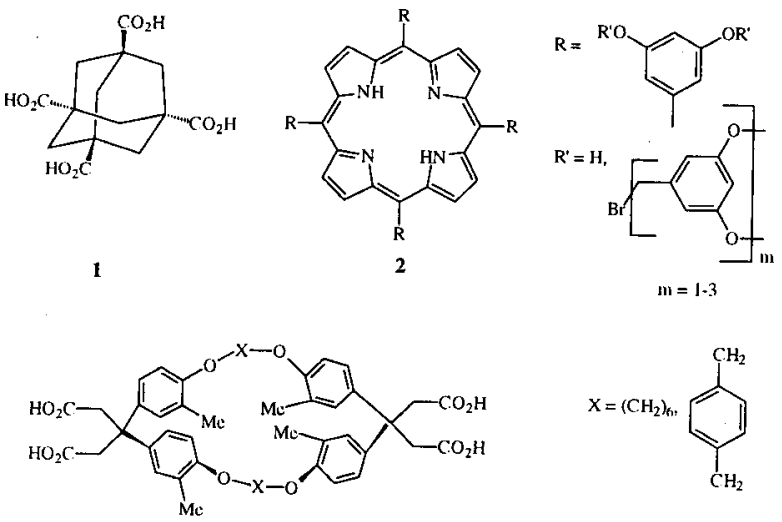

Figura 7. Exemplos de alguns núcleos dendriméricos.

Com o "crescimento" para fora do núcleo, unidades repetitivas são adicionadas sucessivamente. A formação de $c a$ madas interiores dá-se pela adição dessas unidades repetitivas. No primeiro estágio, a adição de uma unidade de repetição ao núcleo central, produz a primeira camada interior, ou geração, $\mathrm{G}$, e, neste caso $\mathrm{G}=1$. O ciclo sucessivo de reações (adição de mais unidades de repetição), cria gerações maiores de dendrímeros. No final do ciclo, uma nova camada externa é formada. Esta camada contém os grupos funcionais terminais. $\mathrm{O}$ número de grupos terminais e a massa molar relativa (RMM), podem ser facilmente obtidos através das seguintes fórmulas:

$$
\begin{gathered}
\mathrm{n}=\mathrm{N}_{\mathrm{c}} \times \mathrm{N}_{\mathrm{b}}{ }^{\mathrm{G}} \\
\mathrm{RMM}=\mathrm{M}_{\mathrm{c}}+\mathrm{N}_{\mathrm{c}}\left[\mathrm{M}_{\mathrm{b}}\left[\mathrm{N}_{\mathrm{b}}{ }^{\mathrm{G}}-1 / \mathrm{N}_{\mathrm{b}}-1\right]+\mathrm{M}_{\mathrm{t}} \mathrm{XN}_{\mathrm{b}}{ }^{\mathrm{G}}\right]
\end{gathered}
$$

onde, $\mathrm{n}=$ número de grupos terminais

$\mathrm{N}_{\mathrm{b}}=$ multiplicidade das ramificações (pontos de ramificação da unidade de repetição)

$\mathrm{N}_{\mathrm{c}}=$ multiplicidade do núcleo central (pontos de ramificação da unidade central)

$\mathrm{G}=$ geração

$\mathrm{M}_{\mathrm{c}}, \mathrm{M}_{\mathrm{b}}$ e $\mathrm{M}_{\mathrm{t}}=$ representam a Massa Molar Relativa do núcleo, da unidade de repetição e dos grupos terminais, respectivamente.

\section{SÍNTESE DENDRIMÉRICA}

Os dendrímeros são sintetizados através de etapas bem controladas. Entretanto, dois métodos diferentes são comuns: (i) o método divergente e (ii) o convergente.

\section{O método divergente $\mathrm{e}^{52,53}$}

O princípio deste método envolve o crescimento de um núcleo central, onde as ramificações são justapostas através de etapas sintéticas repetitivas. Este método é caracterizado por reações que ocorrem por um aumento do número de sítios, como se o dendrímero estivesse sendo construído "de dentro para fora". O procedimento geral é mostrado na figura 6 .

As camadas externas passam a constituir a estrutura interna do dendrímero. Uma característica do método divergente é que há um rápido aumento do número de grupos terminais reativos. Não obstante, quanto mais a molécula cresce, maiores imperfeições e falhas ocorrem. Isto se deve ao fato de que reações incompletas dos grupos terminais podem ser observadas.

\section{$O$ método convergente ${ }^{54-56}$}

A síntese começa pelo que tornar-se-á a "periferia" do dendrímero. O princípio básico do método envolve a construção de 
pequenas unidades fragmentais que são chamadas dendrons. Esses dendrons são então unidos para a constituição do núcleo central e, consequentemente, para a formação final do dendrímero, Figura 8.

3
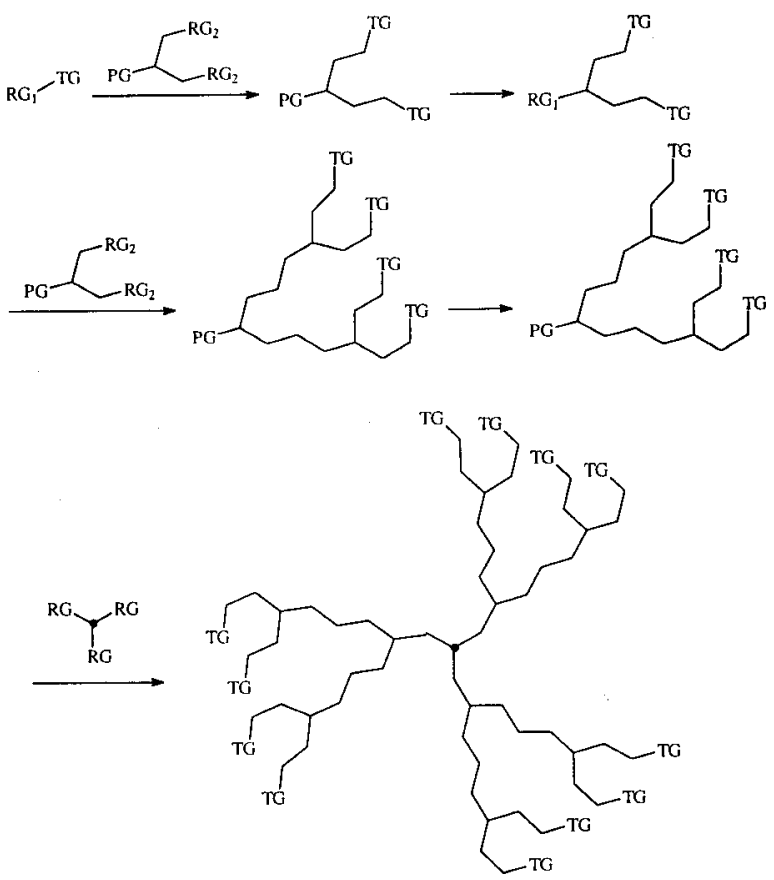

Figura 8. Representação esquemática de uma síntese dendrimérica convergente.

O material de partida contém um grupo reativo (RG1) de um lado da subunidade estrutural e um grupo terminal (TG) na outra extremidade, que constituirá, na geração final, a camada externa do dendrímero. Esse fragmento pode, então, reagir com grupos reativos $\left(\mathrm{RG}_{2}\right)$ da unidade de repetição, que também contêm sítios protegidos (PG). Depois da conversão para um novo grupo reativo $\left(\mathrm{RG}_{2}\right)$ a síntese pode ser continuada por reação com uma segunda unidade de repetição. A repetição do ciclo de desproteção/ reação leva à construção de grandes dendrons. A reação dos dendrons desprotegidos com grupos reativos (RG) de um núcleo terminal, constitui o dendrímero final.

\section{Alguns exemplos da síntese dendrimérica ${ }^{14,}$ 55, 57-59}

As moléculas dendriméricas começaram a atrair atenção em meados dos anos oitenta. Desde então, esta área tem evoluído rapidamente e diferentes tipos de dendrímeros são conhecidos. Alguns exemplos serão mostrados a seguir.

Newkome, usando um processo divergente, sintetizou moléculas dendríticas direcionais em cascatas (ou arboróis) ${ }^{60}$. As "moléculas núcleo" são constituídas de cadeias longas, com um grupo reativo em uma das extremidades, através do qual estendem-se todas as ramificações. Isto leva a uma estrutura tipo "árvore", como ilustra a figura 9.

Newkome e colaboradores também reportaram a primeira síntese de arboróis com esqueletos carbônicos saturados ${ }^{61^{a}}$. Eles têm as características de micelas globulares, Esquema 1. Esse dendrímero forma complexos com moléculas apolares (por exemplo, difenilexatrieno, clorotetraciclina) ${ }^{61}$, que ocupam uma região lipofílica do mesmo. Essas moléculas não formam agregados e podem, portanto, ser consideradas como micelas unimoleculares $61 \mathrm{~b}$

Com o objetivo de mimetizar funções biológicas de hemeproteínas e clorofilas, varias metaloporfirinas estericamente impedidas têm sido sintetizadas ${ }^{62}$. Exemplos mais recentes, incluindo

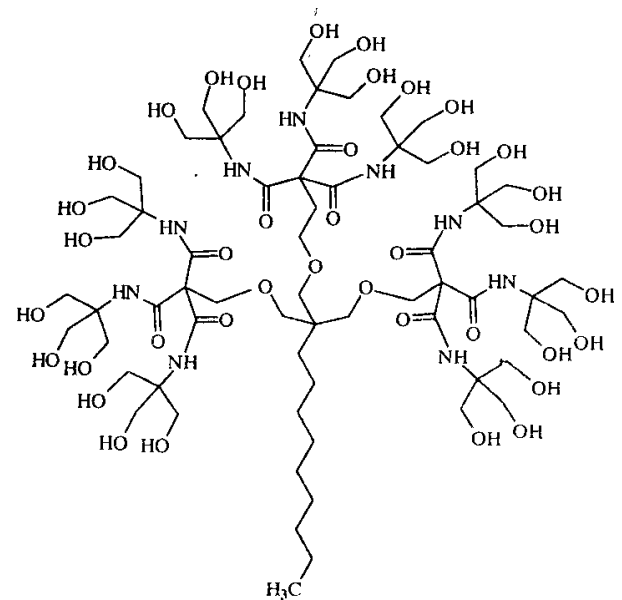

Figura 9. Exemplo de um arborol unidimensional.

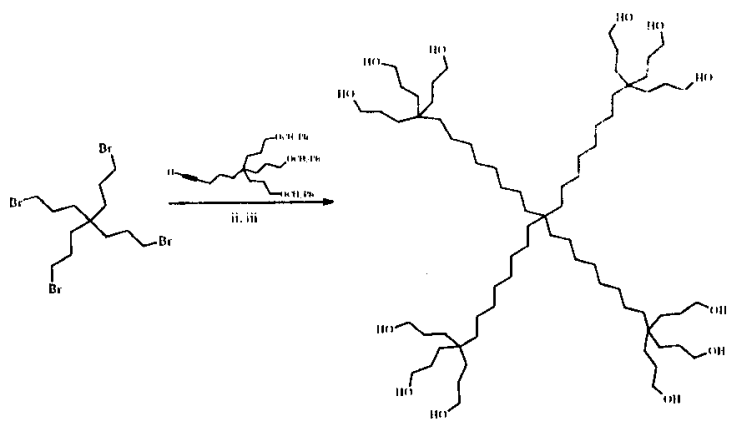

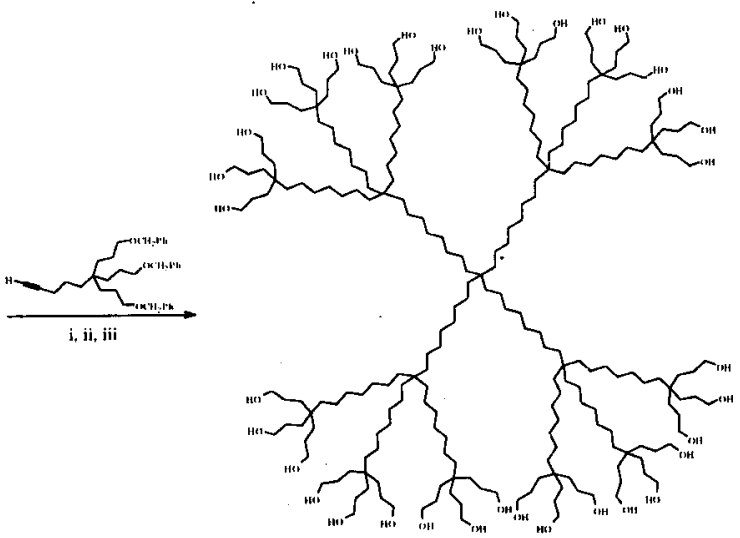

Esquema 1. Preparação de um arborol globular. i. $\mathrm{SOBr}_{2}$; ii. $L D A$; iii. $\mathrm{H}_{2}, \mathrm{Pd} / \mathrm{C}$.

metaloporfirinas ligadas a polipeptídeos ${ }^{63}$ e ciclodextrinas ${ }^{64}$, sugerem a importância do isolamento estérico do núcleo da metaloporfirina na realização de certas funções biológicas. Similarmente, as químicas dendrítica, biológica e sintética têm procurado construir metaloporfirinas como gaiolas dendríticas. Fréchet, elegantemente, sintetizou dendrímeros com núcleos porfirínicos através de uma síntese convergente, figura $10^{65}$.

$\mathrm{O}$ dendrímero mostrado na figura $11^{66-68}$ foi usado nos estudos de formação de complexos com hidrazidas e compostos mesoiônicos, como agente solubilizante de substâncias insolúveis em água e os resultados são a seguir discutidos.

\section{RESULTADOS E DISCUSSÃO}

Um composto de adição é um complexo químico no qual uma molécula está "incluída" dentro de outra molécula ou agregado de 


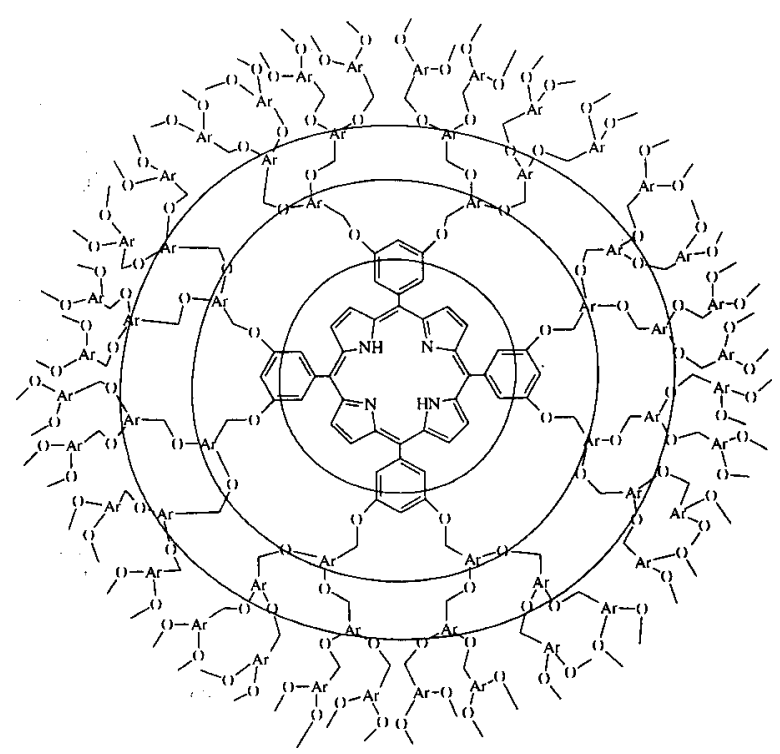

Figura 10. Representação esquemática de um dendrímero. porfirínico.

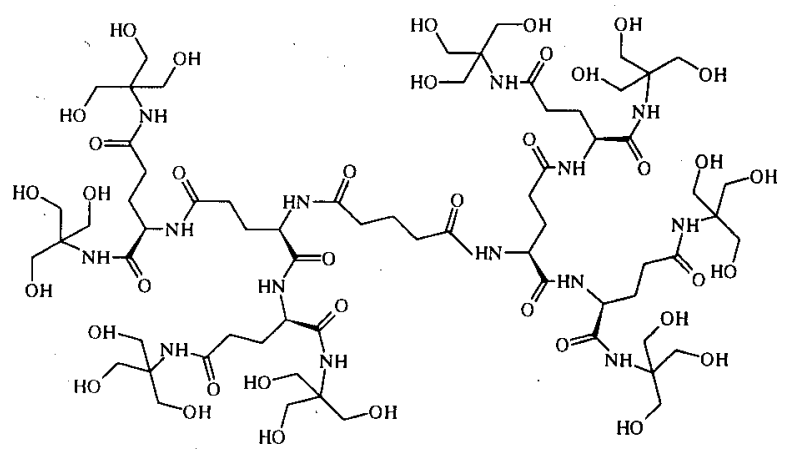

Figura 11. Estrutura química do dendrímero "24-OH".

moléculas, sem que haja perda de massa por sua formação. Os compostos de adição são formados sem que haja a formação de ligações químicas covalentes. Hospedeiro e convidado permanecem, mais ou menos, intatos e, ligações fracas podem mantê-los juntos. O critério essencial é que a molécula "convidada" tenha forma e tamanho (i.e. o melhor preenchimento espacial possível) apropriados para ajustar-se na cavidade de uma estrutura "sólida" formada pela molécula hospedeira. A estereoquímica e, possivelmente, a polaridade de ambas as moléculas determinam se a inclusão ocorre $^{69}$. O contato dos dois componentes produz um complexo de força devida, primariamente, a interações de van der Waals. Quando possível, dipolos altamente orientados podem estabilizar os componentes do complexo que estão interagindo. Este tipo de formação de complexo espacial não ocorre, normalmente, por meio de ligações iônicas, covalentes ou covalente coordenadas (conceitualmente usuais em complexações químicas).

O grau de complexação de moléculas grandes é dependente da presença de grupos apropriados ou anéis capazes de entrar numa cavidade. Somente parte da molécula precisa estar associada com a cavidade do dendrímero e não a molécula toda. Para moléculas com dimensões similares, o resíduo ou moléculas mais lipofílicas têm maior afinidade pela "cavidade" do dendrímero em solução aquosa ${ }^{70}$.

Os complexos de inclusão não são espécies estáticas em solução. Um equilíbrio dinâmico é estabelecido entre as moléculas complexadas e as "convidadas" livres, no ambiente próximo; os substratos incluídos na cavidade permutam rapidamente com os substratos livres. Eles podem adotar diferentes orientações sobre seus eixos ${ }^{71}$. A formação do complexo compreende os seguintes processos elementares ${ }^{69}$ : (i) aproximação do substrato à molécula dendrimérica; (ii) as moléculas de água escapam da cavidade dendrimérica; (iii) a estrutura da água é restabelecida ao redor da parte exposta da molécula do "convidado", depois de ter ocorrido a inclusão.

$\mathrm{Na}$ primeira etapa o fator estérico está envolvido - a estabilidade ou velocidade de formação devem ser dependente da geometria. As outras etapas podem ter como força motriz as interações hidrofóbicas. Além disso, as três etapas são gerais $\mathrm{e}$, portanto, não fornecem qualquer especificidade na velocidade de formação dos complexos.

Outros fatores que afetam a velocidade e a extensão da complexação são: tamanho e geometria; interações de van der Waals e outras forças eletrostáticas, como ligações de hidrogênio, p.e.. Fatores conformacionais também podem afetar a energia de interação. A temperatura e o pH também podem afetar a posição de equilíbrio.

Os complexos foram estudados através da lei de BeerLambert, onde a absorbância e concentração podem ser relacionadas por um simples diagrama bidimensional ${ }^{172}$.

Os complexos de inclusão foram preparados através do método de co-precipitação. Esse método consiste, em geral, do isolamento do composto de inclusão de uma solução saturada de metanol.

Neste estudo os compostos mostrados na figura 12 foram dissolvidos em metanol e em seguida adicionados a uma solução dendrimérica contendo "24-OH" em metanol. A mistura foi mantida sob agitação por períodos que variaram desde 15 minutos até 24 horas. $\mathrm{O}$ solvente foi evaporado a pressão reduzida e o resíduo foi lavado com tampão fosfato (temperatura $=25^{\circ} \mathrm{C}, \mathrm{pH}=$ $7,1)$. Depois de uma agitação vigorosa a solução foi filtrada. A formação do complexo foi estudada por UV após $30 \mathrm{~min}^{73,74}$.

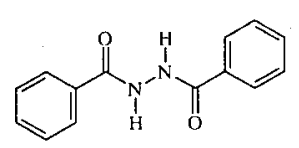

1,2-Dilwenzoilidrazima

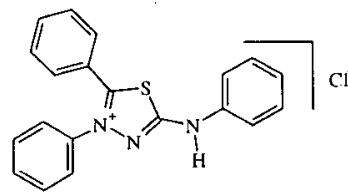

Ácido conjugado do mesoiônico 1,3,4-tiadiazolion-2-aminida
Figura 12. Estruturas da hidrazida e do composto mesoiônico em estudo.

Em geral, a formação do complexo pode resultar em mudanças nos espectros visível ou no ultravioleta. Alguns compostos orgânicos, como fármacos que sejam parcialmente insolúveis em água, apresentam um aumento da solubilidade nesse solvente na presença do dendrímero. Isto se deve ao fato de se formar um complexo entre o fármaco e o dendrímero. A complexação diminui a atividade termodinâmica do fármaco dissolvido. Conseqüentemente, mais fármaco dissolve-se até que a atividade do fármaco livre, que está em equilíbrio químico com o complexo, torna-se igual à atividade termodinâmica da droga como sólido puro.

O composto mesoiônico 1,3,4-tiadiazólio-2-fenilaminida, na sua forma de ácido conjugado, apresenta uma banda a 360,8 nm que é atribuída ao sistema heterocíclico ${ }^{75}$ e uma segunda banda a 260,8 nm atribuída aos anéis fenílicos. Após a formação do complexo, a banda atribuída ao sistema heterocíclico não sofreu qualquer alteração hipso- ou batocrômica. Entretanto, a intensidade da banda atribuída aos grupos fenilas aumentou significativamente e um deslocamento hipsocrômico foi observado e essa banda foi identificada a $223,7 \mathrm{~nm}$. Este resultado torna evidente a formação do complexo. Interessante de se observar é o aumento da intensidade da banda $B$ atribuída aos grupos fenilas. A banda da substância pura apresenta $\varepsilon=453,2$, enquanto que 
aquela devida ao complexo tem $\varepsilon=1.713,3$. Aparentemente, dois mecanismos poderiam operar para justificar esse aumento (efeito hipercrômico): formação de ligação de hidrogênio ou transferência de carga. $\mathrm{O}$ aumento da solubilidade do composto mesoiônico é devido às interações moleculares entre essa droga e o dendrímero.

O método também foi aplicado para o estudo do aumento da solubilidade de hidrazidas com atividade antimicrobiana. $\mathrm{O}$ dendrímero "24-OH" foi inicialmente empregado.

O espectro UV da hidrazida mostra um banda a 290,4 nm, com $\varepsilon=1.442,5$. Após a tentativa de complexação o espectro de UV mostrou uma banda a $291,7 \mathrm{~nm}$, com um $\varepsilon=1.277,5$. Esta pequena diferença de absorção deixa evidente que neste caso não foi possível conseguir-se muita informação sobre a complexação.

Tendo-se em vista que os resultados obtidos para o dendrímero "24-OH" não se mostraram satisfatórios, aventouse a possibilidade de não formação do complexo devido às interações, possivelmente fracas, dos grupos hidroxilas com a hidrazida. Isto evitaria o arranjo apropriado para que o complexo "convidado-hospedeiro" fosse estabelecido. Como alternativa ao reconhecimento molecular necessário para que a complexação ocorresse adequadamente, vislumbramos a possibilidade do uso de outras moléculas dendriméricas, não somente de maior geração mas também com outras características estruturais e físico-químicas, tais como topologia e lipofilia.

Dessa forma, o dendrímero de segunda geração, PAMAM $^{76}$, figura 13 , em solução de álcool metílico a $20 \%$ em peso foi adquirido comercialmente da Aldrich e utilizado sem qualquer manipulação adicional. Esse hospedeiro foi escolhido por conter grupos amida e por ser de segunda geração.

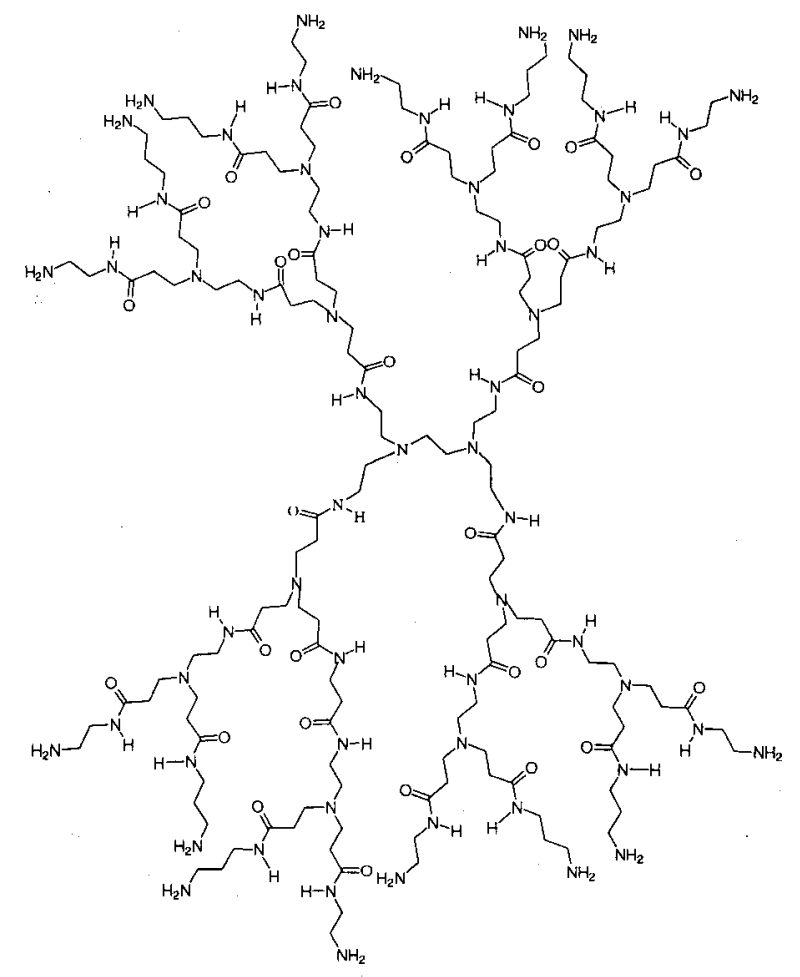

Figura 13. Estrutura $2 D$ do dendrímero PAMAM.

O espectro de absorção em solução metanólica do complexo PAMAM-hidrazida mostrou uma banda de absorção a $329 \mathrm{~nm}$, com um $\varepsilon=7.500$. Esse resultado evidencia claramente que houve um deslocamento batocrômico da absorção da hidrazida quando complexada com o PAMAM. Desse modo, a hidrazida foi complexada e, então, solubilizada.
Ambos os dendrímeros são transparentes nas varreduras exemplificadas.

\section{CONCLUSÃO}

Este trabalho demonstra que moléculas dendriméricas podem ser usadas para a complexação com hidrazidas e também para moléculas como os compostos mesoiônicos.

$\mathrm{O}$ aumento da solubilidade ${ }^{77}$ desses compostos orgânicos pouco solúveis em água foi qualitativamente estabelecido.

O tamanho das cavidades e/ou a constituição lipofílica interna dos dendrímeros - necessária para o estabelecimento de uma região hidrofóbica, parece ser de fundamental importância, assim como os grupos externos que constituem a camada hidrofílica.

Embora os resultados apresentados neste trabalho sejam animadores do ponto de vista de utilização de moléculas dendriméricas como transportadoras de drogas, elas precisam ainda ser avaliadas quanto à possível toxidez.

\section{AGRADECIMENTOS}

Os autores agradecem ao CNPq, CAPES e PRPq-UFMG pelo auxílio financeiro e bolsas de estudos (M. L. C. M. e C. A. M.).

\section{REFERÊNCIAS}

1. Holton, R.; Somoza, C.; Kim, H-B.; Liang, F.; Biediger, R. J.; Boatman, P. D.; Shindo, M.; Smith, C. C.; Kim, S.; Nadizadeh, H.; Suzuki, Y.; Taco, C.; Vu, P.; Tang, S.; Zhang, P.; Murthi, K. K.; Gentile, L. N. e Liu, J. H.; J. Am. Chem. Soc. 1994, 116, 1597 (b) Idem, ibidem, 1599.

2. (a) Tomalia, D. A. e Durst, H. D.; Topics in Current Chemistry 1993, 165, 193 (b) Lehn, J.-M. Science 1993, 260, 1762.

3. Pedersen, C. J.; J. Am. Chem. Soc. 1967, 89, 2495

4. Pedersen, C. J.; Angew. Chem. Int. Ed. Engl. 1988, 27, 7027.

5. Cram, D. J.; Angew. Chem. Int. Ed. Engl. 1986, 25, 1039.

6. Cram, D. J.; Angew. Chem. Int. Ed. Engl. 1988, 27, 1009.

7. (a) Dietrich, B.; Lehn, J-M. e Sauvage, J-P.; Tetrahedron Lett. 1969, 2885 (b) Lehn, J.-M.; Science 1985, 227, 849.

8. Dietrich, B.; Lehn, J-M. e Sauvage, J-P.; Tetrahedron Lett. 1969, 2889.

9. (a) Fersht, A.; "Structure and mechanism" $2^{\text {nd }}$ Ed.; New York: Freeman, 1985 (b) Ladurner, , Itzhaki, L. e Fersht, A.; Protein Eng. 1997, 10, 29.

10. Cram, D. J. e Lein, G. M.; J. Am. Chem. Soc. 1985, 107,3657

11. Cram, D. J.; Acc. Chem. Res. 1978, 11, 8.

12. Zanini, D.; e Roy, R.; J. Am. Chem. Soc. 1997, 119, 2088.

13. Ottaviani, M. F.; Montalti, F.; Turro, N. J. e Tomalia, D. A.; J. Phys. Chem. B 1997, 101, 158.

14. Spetzler, J. C.; e Tam, J. P.; Peptide Res. 1996, 9, 290.

15. Bender, M. L.; e Komiyama, M.; "Cyclodextrin Chemistry", Berlin, Springer, 1978.

16. Atwood, J. L.; Davies, J. E. e MacNicol, D. D.; “Inclusion Compounds", Academic Press, NY, 1984

17. Breslow, R.; Acc. Chem. Res. 1991, 24, 317.

18. Breslow, R.; Science 1982, 218, 532.

19. (a) Diederich, F.; "Cyclophanes" in Monographs in Supramolecular Chemistry, Ed. J. F. Staddart, Cambridge, Royal Society of Chemistry, 1989 (b) Jimenez, L.; e Diederich, F.; Tetrahedron Lett. 1989, 30, 2759 (c) Diederich, F.; e Lutter, H. D.; J. Am. Chem. Soc. 1989, 111, 8438.

20. Sakamoto, Y.; Miyoshi, N.; Hirakida, M.; Kusumoto, S.; Kawase, H.; Ruddzinski, J. M.; e Shynmyozu, T.; J. Am. Chem. Soc. 1996, 118, 12267.

21. Chao, I.; e Diederich, F.; Recl. Trav. Cim Pays-Bas. 1993, 12,335 
22. Ngola, S. M.; e Doughert, D. A.; J. Org. Chem. 1996, $61,4355$.

23. vanBeek, J.; Callender, R.; Gunner, M. R.; Biophys. J. 1997, 72, 619.

24. Luck, W. A. P.; e Klein, D.; J. Mol. Struct. 1996, 381, 83.

25. Roth, C. M.; Neal, B. L.; e Lenhoff, A. M.; Biophys. J. 1996, $70,977$.

26. Earles, T. T.; J. Chem. Ed. 1995, 72, 727.

27. Lloyd, T. B.; Coll. Surf. A-Phys. Eng. Aspec. 1994, $93,25$.

28. Lewis, J. P.; Ordeson, P.; Sankey, O. F.; Phys. Ver. BCondensed Matter 1997, 55, 6880.

29. Michalczyk, R.; Silks, L. A. Russu, I. M.; Magn. Res. Chem. 1996, 34, 597.

30. Hamilton, A. D.; J. Chem. Educ. 1990, 67, 821.

31. Rebeck Jr., J.; Acc. Chem. Res. 1990, 23, 399.

32. Chipot, C.; Jaffe, R.; Maigret, B.; Pearlman, D. A. e Kollman, P. A.; J. Am. Chem. Soc. 1996, 118, 11217.

33. Pirkle, W. H.; e Liu, Y. L.; J. Chromat. A 1996, 747, 19.

34. Olhiai, K.; Mazaki, Y.; e Bayashi, K.; Mol. Crystals Liq. Crystal Sci. Technol. A 1996, 276, 153.

35. Suzuki, S.; Green, P. G.; Bumgarner, R. E.; Dasgupta, S.; Goddard, W. A. III; e Blake, G. A.; Science 1992, 257, 942 .

36. Dougherty, D. A.; Science 1996, 271, 163.

37. Murayama, K. e Aoki, K.; Chem. Commun. 1997, 119.

38. Mecozzi, S.; West, A.P. e Dougherty, D. A.; Proc. Nat. Ac. Sci. U.S.A. 1996, 93, 10566.

39. Caldwell, J. W. e Kollman, P. A.; J. Am. Chem. Soc. 1995, $117,4177$.

40. (a) Gutsche, C. D.; "Calixarenos", em Monographs in Supramolecular Chemistry, Ed. J. F. Staddart. Cambridge, Royal Society of Chemistry, 1989 (b) Xie, D. J. e Gutsche, C. D.; J. Org. Chem. 1997, 62, 2280.

41. Lazzarotto, M.; Nachtigall, F. F. e Nome, F.; Quím. Nova 1995, 18, 444.

42. Arnecke, R.; Bohmer, V.; Lacciopaglia, R.; Cort, A. D.; Tetrahedron 1997, 53, 4901.

43. Zhang, L. S.; e Tam, J. P.; J. Am. Chem. Soc. 1997, 119,2363

44. Brunner, H.; J. Organometal. Chem. 1995, 500, 39

45. Jansen, J. F. G. A.; de Brabander-van den Berg, E. M. M. e Meijer, E. W.; Science 1994, 266, 1226.

46. Jansen, F. F. G. A. e Meijer, E. W.; J. Am. Chem. Soc. 1995, 117, 4417.

47. Tomalia, D. A.; Naylor, A. M.; e Goddard III, W. A.; Angew. Chem. Int. Ed. Engl. 1990, 29138.

48. Newkome, G. R.; Moorfield, C. N.; Baker, G. R. e Behera, R. K.; J. Org. Chem. 1992, 57, 358.

49. (a) Fréchet, J. M. J.; Reported at the International Symposium on Recognition Processes, Birmingham, UK, 1994 (b) Wooley, K. L.; Fréchet, J. M. J.; e Hawker, C. J.; Polymer 1994, 35, 4489 (c) Fréchet, J. M. S.; Science 1994, 263, 1710.

50. Jin, R. H.; Aida, T.; e Inoue, S.; J. Chem. Soc. Chem. Commun. 1993, 1260.

51. (a) Diederich, F.; Reported at the International Symposium on Recognition Processes, Birmingham, UK, 1994 (b) Diederich, F.; e Carcanague, D. R.; Helv. Chim. Acta 1994, 77, 800 .
52. Newkome, G. R.1 Yao, Z. O.; Baker, G. R.; e Gupta, V. K.; J. Org. Chem. 1985, 50, 2003.

53. Tomalia, D. A.; Baker, H.; Hall, M.; Kallos, G.; Martin, S.; Roek, J.; e Smith, P.; Polym. J. 1985, 17, 117.

54. Hawker, C. J.; e Fréchet, J. M. J.; J. Am. Chem. Soc. 1990, 15, 4375.

55. Balagurusami, V. S. K.; Ungar, G.; Percec, V.; e Johansson, G.; J. Am. Chem. Soc. 1997, 119, 1539.

56. Bo, Z. S.; Zhang, X.; Yi, X. B.; Yang, M. L.; Shen, S. C.; Rehn, Y. H.; e Xi, S. Q.; Polymer Bull. 1997, 38, 257.

57. Kim, C.; e An., K.; Bull. Korean Chem. Soc. 1997, 18, 164.

58. McElhanon, J. R.; Wu, M. J.; Escobar, M.; Chaudry, U.; Hu, C. L.; e McGrath, D. V.; J. Org. Chem. 1997, 62, 908.

59. Mulders, S. J. E.; Brower, A. J.; vanderMeer, P. G. J.; Liskamp, R. M. J.; Tetrahedron Lett. 1997, 38, 631.

60. Newkome, G. R.; Yao, Z. Q.; Baker, G. R.; e Gupta, V. K.; J. Org. Chem. 1995, 50, 2003.

61. (a) Newkome, G. R.; Moorefield, C. N.; Baker, G. R.; Johnson, A. L.; e Bahera, R. K.; Angew. Chem. Int. Ed. Engl. 1991, 30, 1176 (b) Kimura, M; Nakada, K.; Yamaguchi, Y.; Hanabusa, K.; Shirai, H.; e Kobayashi, N.; Chemm. Comm. 1997, 1215, e referências citadas.

62. Simonis, U.; Walker, F. A.; Lee, P. L.; Hanquet, B. J.; Meyerhoff, D. J.; e Scheidt, W. R.; J. Am. Chem. Soc. 1987, 109, 2659.

63. Akerfeldt, K. S.; Kim, R. M.; Camac, D.; Groves, J. T.; Lear, J. M.; e DeGrado, W. F.; J. Am. Chem. Soc. 1992 , 114,9656

64. Dick, D. L.; Rao, T. V.; Sukumuran, D.; e Lawrence, D.; J. Am. Chem. Soc. 1992, 114, 2664.

65. (a) Fréchet, J. M. J.; International Symposium on Recognition Processes, Birmingham, U.K., 1994 (b) Pollak, K. W.; Leon, J. W.; e Fréchet, J. M. J.; Abs. Papers Am. Chem. Soc. 1995, 210, pp. 177-PMSE (c) Fréchet, J. M. J.; Science 1994, 263, 1710 (d) Sadamoto, R.; Tomioka, N. e Ainda, T.; J. Am. Chem. Soc. 1996, 118,3978 e referências citadas.

66. Lance, T.; Tese de Ph. D., University of Kent at Canterbury, 1995.

67. Fréchet, J. M. J.; Science 1994, 263, 1710.

68. Naylor, A. M.; Goddard III, W. A.; Kiefer, G. E. e Tomalia, D. A.; J. Am. Chem. Soc. 1989, 111, 2339.

69. Cramer, F.; e Spatz, H. C.; J. Am. Chem. Soc. 1967, 89, 14.

70. Loftsson, T. e Bodor, N.; Acta Pharm. Nord. 1989, 1, 185.

71. Friedman, R. B.; Hedges, A. R.; e Reed, G. A.; Proceed. Int. Symp. Control Rel. Bioact. Mater.; 1987, 14, 311.

72. (a) Freifelder, D. em Physical Biochemistry. Applications to Biochemistry em Molecular Biology. $2^{\text {nd }}$ Ed., W. H. Freeman and Company, N.Y., 1982, pp. 494-536. (b) Szejtli, J.. Cyclodextrin and their inclusion complexes. Akadémiai Kiadó, 1982, Budapest, 13-109.

73. Hirayama, F.; Hirashima, N.; Ijitsu, T. e Ueno, M.; J. Pharm. Sci. 1988, 77, 233.

74. Szejtli, J.; Akadémiai Kiadó, Budapest, 1982, 162.

75. Montanari, C. A.; Myiata, Y.; Sandall, J. P. B.; Kyian, N. Z. e Miller, J.; Quím. Nova, 1993, 16, 404.

76. Tabakovic, I.; Miller, L. L. Dvan, R. G.; Tully, D. C. e Tomalia, D. A.; Chem. Mat. 1997, 9, 736.

77. Kuzdal, S. A.; Monning, C. A.; Newkome, G. R.; e Moorefield, C. N.; J. Am. Chem. Soc. 1997, 119, 2255. 